\title{
Phase I Study Evaluating the Combination of Afatinib with Carboplatin and Pemetrexed After First-line EGFR-TKIs
}

\author{
SATOSHI WATANABE ${ }^{1}$, OU YAMAGUCHI ${ }^{2}$, AI MASUMOTO ${ }^{2}$, YURI MAENO ${ }^{2}$, \\ YOSUKE KAWASHIMA $^{3}$, OSAMU ISHIMOTO ${ }^{3}$, SHUNICHI SUGAWARA $^{3}$, HIROHISA YOSHIZAWA ${ }^{1}$, \\ TOSHIAKI KIKUCHI ${ }^{1}$, TOSHIHIRO NUKIWA ${ }^{4}$ and KUNIHIKO KOBAYASHI ${ }^{2}$ \\ ${ }^{1}$ Department of Respiratory Medicine and Infectious Diseases, \\ Niigata University Graduate School of Medical and Dental Sciences, Niigata, Japan; \\ ${ }^{2}$ Respiratory Medicine, Saitama Medical University International Medical Center, Saitama, Japan; \\ ${ }^{3}$ Department of Pulmonary Medicine, Sendai Kousei Hospital, Sendai, Japan; \\ ${ }^{4}$ Japan Anti-Tuberculosis Association, Tokyo, Japan
}

\begin{abstract}
Background/Aim: Promising reports have described the combination of first-generation epidermal growth factor receptor tyrosine-kinase inhibitors (EGFR-TKIs) with carboplatin plus pemetrexed or bevacizumab. However, no analysis of afatinib with platinum-doublet chemotherapies has been performed. Patients and Methods: We evaluated the safety and antitumor efficacy of afatinib combined with carboplatin and pemetrexed in EGFR-mutated non-small-cell lung cancer (NSCLC) patients who progressed during first-generation EGFR-TKIs. Results: Ten patients received 20 or $30 \mathrm{mg} /$ day afatinib with carboplatin (area under the curve, 5) and pemetrexed $\left(500 \mathrm{mg} / \mathrm{m}^{2}\right)$. Dose-limiting toxicities included delay of afatinib $\geq 14$ days, grade 3 diarrhea, grade 3 hypokalemia, grade 3 serum amylase increase and grade 4 thrombocytopenia. The recommended dose of afatinib was $20 \mathrm{mg} /$ day in this combination therapy. Overall response rate was $30 \%$ and median progression-free survival was 13.7 months. Conclusion: This is the first study to investigate the combination of afatinib, carboplatin and pemetrexed. At the recommended dose, this combination was well tolerated and had a good clinical efficacy.
\end{abstract}

Epidermal growth factor receptor (EGFR) tyrosine-kinase inhibitors (TKIs) have shown improvements in progressionfree survival (PFS) and response rates compared to platinum-

This article is freely accessible online.

Correspondence to: Kunihiko Kobayashi, Respiratory Medicine, Saitama International Medical Center, 1397-1, Yamane, Hidaka City, Saitama, 350-1298, Japan. Tel: +81 429849111, Fax: +81 429844111, e-mail: kobakuni@ saitama-med.ac.jp

Key Words: Afatinib, carboplatin, pemetrexed, EGFR mutation, non-small-cell lung cancer. doublet therapy in EGFR-mutation-positive non-small-cell lung cancer (NSCLC) (1-6). Despite the excellent efficacy of EGFR-TKIs in EGFR-mutation-positive NSCLC, almost all patients experience resistance to EGFR-TKIs. Osimertinib therapy for relapsed patients with the T790M mutation after 1st and 2nd generation EGFR-TKI (gefitinib, erlotinib and afatinib) treatments has been established, but no standard therapies have been developed for NSCLC patients without T790M after failure of first-line EGFR-TKIs.

Previous studies reported that even when NSCLC patients with EGFR mutations showed radiographic disease progression during EGFR-TKI therapy, NSCLC remained sensitive to EGFR-TKIs (7). Riely et al. demonstrated that NSCLC showed significant proliferation after discontinuation of EGFR-TKIs using positron emission tomography imaging (8). Additionally, Chaft et al. reported that some patients who had developed acquired resistance to EGFR-TKI treatments showed rapid disease progression when EGFR-TKI administration was stopped (9). These findings indicate that there is a heterogeneous mixture of TKI-sensitive and TKI-resistant lung cancer cells in EGFR-mutated patients with disease progression while on EGFR-TKI therapy. Indeed, continuation of gefitinib beyond disease progression has shown favorable results (10-12). The addition of cytotoxic agents to EGFR-TKI therapy in patients who had benefited from initial EGFR-TKI treatment appears to be a promising approach because EGFR-TKI inhibits TKIsensitive cancer cells and cytotoxic chemotherapy can target EGFR-TKI-resistant cells.

Afatinib is a second-generation, irreversible EGFR-TKI. In a phase I/II study, afatinib showed antitumor effects in EGFR-mutated NSCLC patients previously treated with firstgeneration EGFR-TKIs. The results from large randomized phase II and phase III studies have indicated that afatinib has better antitumor activities than gefitinib $(5,6,13)$. We previously reported that the combination of gefitinib, 
carboplatin and pemetrexed had promising antitumor effects for patients with $E G F R$-mutations in a first-line setting (14). Our randomized phase III study demonstrated that the combination of gefitinib, carboplatin and pemetrexed significantly prolonged overall survival (OS) compared to gefitinib monotherapy (52.2 months vs. 38.8 months, $p=0.013$ ) (15). These findings indicate that the combination of afatinib, carboplatin and pemetrexed might improve clinical outcomes for NSCLC patients with EGFR-mutations after failure of first-line EGFR-TKI treatment. Furthermore, afatinib and the combination of carboplatin and pemetrexed did not share mechanisms of inhibition in lung cancer cells and did not have similar profiles of adverse events. Also, there have been no reports describing afatinib combined with platinum-doublet chemotherapy in lung cancer patients.

Here a phase I study was conducted to evaluate the safety, tolerability and antitumor efficacy of the combination treatment of afatinib, carboplatin and pemetrexed in EGFRmutated NSCLC patients who showed disease progression during first-generation EGFR-TKI treatment.

\section{Patients and Methods}

Patient selection. Patients were 20-75 years old at the time of provision of informed consent, had an Eastern Cooperative Oncology Group Scale of performance status (PS) of 0 to 1, had measurable disease according to Response Evaluation Criteria in Solid Tumors (RECIST) version 1.1, and had a life expectancy of at least 3 months (16). Eligible criteria also included a confirmed histological or cytological diagnosis of non-squamous NSCLC that was treated with gefitinib or erlotinib as the first-line treatment and then showed disease progression, common activating EGFR mutations (exon 19 deletion or L858R), either postoperative recurrence or stage IIIB or IV, and adequate major organ function. Patients who had previously received afatinib or cytotoxic chemotherapy for advanced disease, had symptomatic brain metastases and had pulmonary fibrosis or interstitial-lung disease were excluded.

All patients provided written informed consent. The study was conducted in accordance with the Helsinki Declaration of the World Medical Association. The protocol was approved by the institutional review board of each participating institution. This trial was registered at the University Hospital Medical Information Network Clinical Trial Registry (UMIN 000015582).

Study design and treatment procedure. This was a multicenter phase I study across institutions belonging to the North East Japan Study Group. In a 3+3 dose escalation design, patients were treated with carboplatin (area under the curve $[\mathrm{AUC}]=5$ ) and pemetrexed $\left(500 \mathrm{mg} / \mathrm{m}^{2}\right)$ on day 1 of a 21 -day cycle. Afatinib was given on days 8 to 18 and escalated from 20 to $40 \mathrm{mg} /$ day. After 4 to 6 cycles of the combination treatment of the three-drug regimen, 500 $\mathrm{mg} / \mathrm{m}^{2}$ pemetrexed on day 1 and afatinib administration on days 8 to 18 every 21 days were continued for maintenance.

Patients received folic acid and vitamin B12 at least 7 days before the start of the first cycle, and these treatments continued to be administered every day and every 9 weeks, respectively. When carboplatin and pemetrexed were administered on day 1 , the patient must have been afebrile and have PS 0-2, grade 1 or less neutropenia, thrombocytes $\geq 100,000 / \mu 1$, creatinine $\leq 1.5 \mathrm{mg} / \mathrm{dl}$, and both aspartate aminotransferase and alanine aminotransferase $\leq 3$ times the upper limits of normal. Afatinib administration was delayed in the presence of toxicities, such as PS $\leq 3$, neutropenia grade $\geq 3$, thrombocytopenia $<75,000 / \mu 1$, diarrhea grade $\geq 2$ or non-hematological toxicities $\geq 3$. Prophylactic administration of loperamide was allowed.

Carboplatin and/or pemetrexed dose reductions were performed in each subsequent cycle in the event of severe toxicities in the previous cycle, including thrombocytopenia $<25,000 / \mu 1$, febrile neutropenia, grade $\geq 2$ sensory neuropathy or other grade $\geq 3$ nonhematological toxicities. A dose reduction comprised a decrease in carboplatin dosing to an AUC of $4 \mathrm{mg} / \mathrm{ml} / \mathrm{min}$ and a decrease in pemetrexed to $400 \mathrm{mg} / \mathrm{m}^{2}$. Subsequent dose increases were not allowed after a reduction in the chemotherapy dose.

Definition of dose-limiting toxicity (DLT) and maximum-tolerated dose (MTD). All toxicities were graded using Common Terminology Criteria for Adverse Events version 4.0. A dose-limiting toxicity (DLT) was defined as grade 4 thrombocytopenia, grade 4 neutropenia if longer than 7 days, febrile neutropenia, grade 3 or 4 non-hematologic toxicity, diarrhea grade $\geq 2$ for more than 4 days despite supportive care, nausea and/or vomiting grade $\geq 2$ for $\geq 7$ days, cardiac left ventricular function grade $\geq 2$, delay of next treatment cycle $\geq 21$ days, and delay of afatinib treatment $\geq 14$ days.

The primary endpoint of this study was to determine the maximumtolerated dose (MTD) and recommended dose (RD) of afatinib in combination with pemetrexed and carboplatin. Cohort expansion to six patients was required if one DLT was observed in the first three patients, and dose escalation would be stopped if more than half of the patients experienced DLTs. The MTD was defined as the lowest dose at which $\geq$ three of six patients experienced DLT during the first cycle.

Antitumor activities. Tumor response was assessed according to RECIST version 1.1 and classified as complete response (CR), partial response (PR), stable disease (SD) and progressive disease (PD) by an extramural review process. PFS was defined as the time from registration to the date of initial disease progression or death, whichever occurred first, and PFS data were estimated using Kaplan-Meier methodology. OS was defined as the time from registration to death from any cause.

\section{Results}

Patient characteristics. Between November 2014 and June 2016, 11 patients were enrolled: 3 patients at dose level 1 (afatinib at $20 \mathrm{mg} /$ day, pemetrexed and carboplatin) and 8 patients at dose level 2 (afatinib at $30 \mathrm{mg}$ /day, pemetrexed and carboplatin). Because one patient did not receive the protocol therapy due to severe infection at dose level 2, safety and efficacy were assessed in 10 total patients (Table I). Tumor genotyping revealed that 8 patients had exon 19 deletions, and 2 patients had L858R. Seven patients had previously received gefitinib, and 3 had received erlotinib as the first-line treatment. All patients had benefitted from prior EGFR-TKIs.

Safety and MTD. All 10 patients experienced an adverse event (AE) in all treatment courses, with leukocytopenia and neutropenia being the most frequently reported (Table II). 
Table I. Demographic and baseline characteristics.

\begin{tabular}{|c|c|}
\hline & $\mathrm{N}=10$ \\
\hline \multicolumn{2}{|l|}{ Age } \\
\hline Median & 57 \\
\hline Range & $40-71$ \\
\hline \multicolumn{2}{|l|}{ Gender } \\
\hline Female & 8 \\
\hline Male & 2 \\
\hline \multicolumn{2}{|c|}{ ECOG performance status } \\
\hline 0 & 6 \\
\hline 1 & 4 \\
\hline \multicolumn{2}{|l|}{ Smoking status } \\
\hline Never smoked & 7 \\
\hline Smoker & 3 \\
\hline \multicolumn{2}{|l|}{ Stage (UICC ver.7) } \\
\hline IV & 8 \\
\hline Postoperative & 2 \\
\hline \multicolumn{2}{|l|}{ Tumor histology } \\
\hline Adenocarcinoma & 10 \\
\hline \multicolumn{2}{|c|}{$E G F R$-mutation status } \\
\hline 19 deletion & 8 \\
\hline L858R & 2 \\
\hline \multicolumn{2}{|l|}{ Prior EGFR-TKIs } \\
\hline Gefitinib & 7 \\
\hline Erlotinib & 3 \\
\hline \multicolumn{2}{|c|}{ Best response to prior EGFR-TKIs } \\
\hline $\mathrm{CR}$ & 1 \\
\hline PR & 8 \\
\hline NE & 1 \\
\hline \multicolumn{2}{|c|}{ Stating dose of afatinib } \\
\hline $20 \mathrm{mg} /$ day & 3 \\
\hline $30 \mathrm{mg} /$ day & 7 \\
\hline
\end{tabular}

ECOG: Eastern Cooperative Oncology Group; UICC: the Union for International Cancer Control's; EGFR-TKI: epidermal growth factor receptor tyrosine kinase inhibitor; CR: complete response; PR: partial response; NE: not evaluable.

Diarrhea occurred in 4 patients at all dose levels, especially in the first cycle; however, only one patient had grade 3 diarrhea. Because no DLTs were observed in the 3 patients at dose level 1, escalation to dose level 2 was performed. One of the first three patients at dose level 2 experienced DLT with grade 3 diarrhea (Table III), and, therefore, an additional cohort was treated with the same dose level. One patient of an additional cohort did not receive afatinib due to grade 3 neutropenia during the first treatment cycle. Because recovery from neutropenia was delayed, this patient was not given afatinib in the first cycle. But in subsequent cycle under leukopenia induced by carboplatin and pemetrexed, the patient was treated by afatinib without any severe side effects. The independent data monitoring committee (IDMC) of the study then decided to remove the administration delay criteria of afatinib in the presence of neutropenia, which was approved by each IRB. IDMC also decided to collect a total
Table II. Adverse events in all treatment cycles.

\begin{tabular}{|c|c|c|c|c|}
\hline \multirow[t]{2}{*}{ Adverse event } & \multicolumn{2}{|c|}{$\begin{array}{l}\text { Afatinib } 20 \mathrm{mg} \\
\quad(\mathrm{N}=3)\end{array}$} & \multicolumn{2}{|c|}{$\begin{array}{c}\text { Afatinib } 30 \mathrm{mg} \\
(\mathrm{N}=7)\end{array}$} \\
\hline & $\begin{array}{c}\text { Grade } \\
1 / 2\end{array}$ & $\begin{array}{l}\text { Grade } \\
\geq 3\end{array}$ & $\begin{array}{c}\text { Grade } \\
1 / 2\end{array}$ & $\begin{array}{c}\text { Grade } \\
\geq 3\end{array}$ \\
\hline Leukocytopenia & 1 & 1 & 2 & 4 \\
\hline Neutropenia & 0 & 3 & 1 & 6 \\
\hline Anemia & 2 & 0 & 3 & 0 \\
\hline Thrombocytopenia & 1 & 0 & 3 & 2 \\
\hline Febrile neutropenia & 0 & 0 & 0 & 0 \\
\hline Stomatitis & 2 & 0 & 1 & 0 \\
\hline Appetite loss & 2 & 0 & 4 & 0 \\
\hline Nausea/vomiting & 1 & 0 & 2 & 0 \\
\hline Diarrhea & 1 & 0 & 3 & 1 \\
\hline Constipation & 3 & 0 & 3 & 0 \\
\hline Rash/acne & 2 & 0 & 0 & 0 \\
\hline Fatigue & 2 & 0 & 1 & 0 \\
\hline Blood bilirubin increased & 0 & 0 & 1 & 0 \\
\hline AST/ALT elevation & 1 & 0 & 2 & 1 \\
\hline$\gamma$-glutamyl transferase increased & 0 & 0 & 0 & 1 \\
\hline Serum amylase increased & 0 & 0 & 0 & 1 \\
\hline Creatinine elevation & 1 & 0 & 3 & 0 \\
\hline Hyperkalemia & 0 & 0 & 1 & 0 \\
\hline Hyponatremia & 0 & 0 & 1 & 0 \\
\hline Hypokalemia & 0 & 0 & 0 & 1 \\
\hline Bronchial infection & 0 & 0 & 1 & 0 \\
\hline
\end{tabular}

AST: Aspartate aminotransferase; ALT: alanine aminotransferase.

Table III. Summary of DLTs.

Afatinib dose $30 \mathrm{mg} / \mathrm{day}$

Grade 3 diarrhea

Delay of afatinib $\geq 14$ days

Grade 3 non-hematological toxicity (hypokalemia)

Grade 3 non-hematological toxicity (serum amylase increased) ${ }^{1}$

Grade 4 thrombocytopenia 1

DLT: Dose limiting toxicity. No DLTs occurred at the dose of $20 \mathrm{mg} /$ day. ${ }^{1}$ These DLTs were observed in one patient.

Table IV. Best response to treatment.

\begin{tabular}{lcc}
\hline & All patients $(\mathrm{N}=10)$ & At the RD \\
\hline Complete response & 1 & 0 \\
Partial response & 2 & 2 \\
Stable disease & 7 & 1 \\
Progressive disease & 0 & 0 \\
Overall response rate & $30 \%$ & $67 \%$ \\
Disease control rate & $100 \%$ & $100 \%$ \\
\hline
\end{tabular}

RD: Recommended dose. 


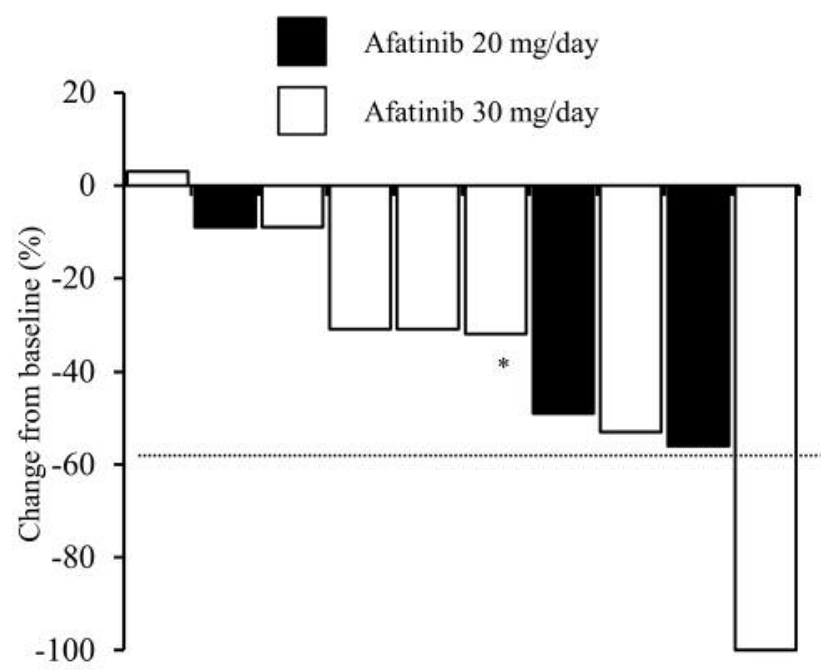

Figure 1. Waterfall plot of the best percentage change of individual patients by the doses of afatinib. *The tumor response was ongoing at the data cutoff in the patient.

of 7 patients in level 2. Two of the additional 4 patients experienced DLTs with grade 4 thrombocytopenia, grade 3 hypokalemia and grade 3 serum amylase increase. Three out of the 6 patients excluding the above patient experienced DLTs. Even in an intent-to-treat population, 4 out of 7 patients at level 2 developed DLTs. Thus, we determined that dose level 2 was the MTD, and dose level 1 with no DLTs was recommended for phase II trials. Median dose intensity, which was the actual dose delivered as a proportion of the planned dose, was $88 \%$ at level 1 and $73 \%$ at level 2 .

Antitumor activities. The median number of cycles administered was 5 (range $=1-19$ cycles). The best confirmed response was $\mathrm{CR}$ in one patient, $\mathrm{PR}$ in 2 patients and $\mathrm{SD}$ in 7 patients of the 10 patients evaluable for radiographic response (Table IV). Notably, the disease-control rate $(\mathrm{DCR}=\mathrm{CR}+\mathrm{PR}+\mathrm{SD})$ was $100 \%$, and no patients showed PD. Tumor shrinkages were observed in all patients except one, and as of September 2017, response was still ongoing in one patient (Figure 1). At the cut-off date for data collection, the median follow-up time was 22.5 months (range=11-30 months). The median PFS was 13.7 months (95\% confidence interval=4-18.2), and 1-year survival was $100 \%$ (Figure 2). Of the 10 patients, only 2 patients died before data cutoff.

\section{Discussion}

The promising antitumor efficacies of the combination of gefitinib, carboplatin and pemetrexed have been described in EGFR-mutated NSCLC patients (14). In addition, our randomized phase III study demonstrated that the combination

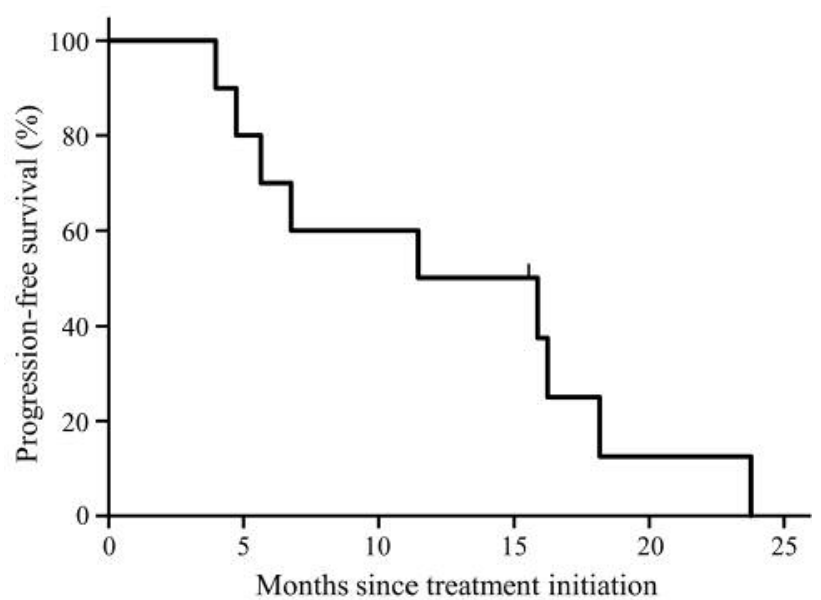

Figure 2. Kaplan-Meier analysis of progression-free survival.

of gefitinib, carboplatin and pemetrexed significantly prolonged OS compared to gefitinib monotherapy (52.2 months vs. 38.8 months, $p=0.013$ ) (15). This study investigated the safety and efficacy of the combination of afatinib, carboplatin and pemetrexed in EGFR-mutated NSCLC patients who received first-generation EGFR-TKIs and showed disease progression. Although AEs frequently observed in afatinib treatment do not overlap with AEs observed in the combination of carboplatin and pemetrexed, we expected that gastrointestinal toxicities, especially appetite loss, nausea and vomiting, would be enhanced by co-administration of afatinib, carboplatin and pemetrexed. Gastrointestinal toxicities are predominantly observed in the 7 days after the start of platinum-doublet therapy. In addition, the half-life of afatinib was 34 to $40 \mathrm{~h}$ in Japanese patients. To avoid the enhancement of gastrointestinal toxicities by the combination of afatinib, carboplatin and pemetrexed, we administered afatinib on days 8 to 18. In this combination therapy, the most common treatment-related AEs included neutropenia, thrombocytopenia, appetite loss and diarrhea. These events were manageable with standard supportive therapies. The MTD of afatinib in this combination was $30 \mathrm{mg} /$ day. Thus, $20 \mathrm{mg} /$ day afatinib (on days 8 to 18 ) with carboplatin (AUC $=5$ ) and pemetrexed (500 $\mathrm{mg} / \mathrm{m}^{2}$ ) was determined as the RD for a phase II trial.

Post hoc analyses of the randomized studies revealed that dose reduction occurred in $53.3 \%$ and $28 \%$ of patients in the LUX-Lung 3 and 6 trials respectively (17). Subgroup analysis of LUX-Lung 3 showed that Japanese patients were more likely to have an AE leading to dose reduction. Indeed, 23 out of 54 Japanese patients needed a dose reduction to $20 \mathrm{mg}$ /day in LUX-Lung 3 (18). Importantly, these studies showed that the dose reduction of afatinib did not decrease the antitumor effects of afatinib $(17,18)$. In the current study, $30 \mathrm{mg} /$ day 
afatinib combined with carboplatin and pemetrexed was not tolerated, and the RD of afatinib was determined to be 20 $\mathrm{mg}$ /day. Although no conclusions can be drawn from this phase I trial, the available data suggested that this combination therapy had good antitumor effects. Long PFS and OS were observed, and all patients except one showed a decrease in tumor size. Similar to the previous findings, good clinical responses were observed at these dose levels in our study.

A randomized phase III trial demonstrated that osimertinib had greater antitumor effects than platinum-doublet therapy in NSCLC patients with the EGFR T790M mutation after failure of first-line EGFR-TKIs (19). In clinical practice, platinumdoublet treatment with/without bevacizumab is administered to patients without the T790M mutation; however, prognosis of these patients is poor, and new treatment strategies are needed. Continuation of gefitinib with the combination of cisplatin and pemetrexed was investigated in patients with EGFR-mutations after the failure of gefitinib (20). Although this combination therapy failed to improve the overall survival, subgroup analyses demonstrated a longer PFS in patients without the T790M mutation (21). Afatinib previously showed some antitumor effects in NSCLC patients who progressed during prior gefitinib and/or erlotinib treatment (22). This study included both EGFR T790M positive and negative patients. These findings might possibly explain the high DCR and long PFS of the combination of afatinib, carboplatin and pemetrexed in the current study. We did not examine the EGFR T790M mutation status because tests for T790M were not covered by the national health insurance in Japan when patients were enrolled. Future studies are necessary to clarify the relationship between the T790M status and the antitumor effects of the combination of afatinib, carboplatin and pemetrexed after failure of first-line EGFR-TKI treatment.

\section{Conclusion}

This phase I study established the safety and tolerability of the combination of afatinib, carboplatin and pemetrexed with promising clinical efficacy. To the best of our knowledge, this is the first study to assess afatinib combined with platinum-doublet chemotherapy. Further evaluation of this combination therapy in EGFR-mutated NSCLC patients after failure of first-line EGFR-TKIs, especially in patients without the EGFR T790M mutation, is warranted.

\section{Conflicts of Interest}

SW reports grants from Boehringer Ingelheim, during the conduct of the study; grants and personal fees from Boehringer Ingelheim, personal fees from Chugai Pharma, Ono Pharmaceutical, Lilly, AstraZeneca, Taiho Pharmaceutical, Pfizer, Bristol-Myers Squibb and Novartis Pharma. OY reports grants and personal fees from Boehringer Ingelheim, during the conduct of the study; personal fees from Ono Pharmaceutical, Bristol-Myers Squibb and AstraZeneca.
AM reports grants from Boehringer Ingelheim, during the conduct of the study. YM reports grants from Boehringer Ingelheim, during the conduct of the study. YK reports grants from Boehringer Ingelheim, during the conduct of the study. OI reports grants from Boehringer Ingelheim, during the conduct of the study. SS reports grants and personal fees from Boehringer Ingelheim, during the conduct of the study; personal fees from AstraZeneca, Chugai Pharma, Pfizer, Taiho Pharmaceutical, Lilly, Novartis Pharma, Kyowa Hakko Kirin, BristolMyers Squibb, Ono Pharmaceutical and MSD. HY reports grants from Boehringer Ingelheim, during the conduct of the study; personal fees from Novartis Pharma, AstraZeneca, Taiho Pharmaceutical, Pfizer, MSD and SHIONOGI \& CO., LTD. TK reports grants from Boehringer Ingelheim, during the conduct of the study; grants from Taiho Pharmaceutical, Chugai Pharma, Lilly and MSD. TN reports grants from Boehringer Ingelheim, during the conduct of the study. KK reports grants from Boehringer Ingelheim, during the conduct of the study; personal fees from Boehringer Ingelheim, Chugai Pharma, Ono Pharmaceutical, Lilly, AstraZeneca and Bristol-Myers Squibb.

\section{Acknowledgements}

The Authors are grateful to the patients and their families and the investigators, nurses, and staff members who participated in the current study. The study was funded by Boehringer Ingelheim. The collection of data used in this analysis was supported by the Tokyo Cooperative Oncology Group. All Authors made the final decision to submit the report for publication. The corresponding Author had full access to all the data in the study and had final responsibility for the decision to submit for publication.

\section{References}

1 Maemondo M, Inoue A, Kobayashi K, Sugawara S, Oizumi S, Isobe H, Gemma A, Harada M, Yoshizawa H, Kinoshita I, Fujita Y, Okinaga S, Hirano H, Yoshimori K, Harada T, Ogura T, Ando M, Miyazawa H, Tanaka T, Saijo Y, Hagiwara K, Morita S and Nukiwa T: Gefitinib or chemotherapy for non-small-cell lung cancer with mutated EGFR. N Engl J Med 362(25): 2380-2388, 2010.

2 Mitsudomi T, Morita S, Yatabe Y, Negoro S, Okamoto I, Tsurutani J, Seto T, Satouchi M, Tada H, Hirashima T, Asami K, Katakami N, Takada M, Yoshioka H, Shibata K, Kudoh S, Shimizu E, Saito H, Toyooka S, Nakagawa K and Fukuoka M: Gefitinib versus cisplatin plus docetaxel in patients with nonsmall-cell lung cancer harbouring mutations of the epidermal growth factor receptor (wjtog3405): An open label, randomised phase 3 trial. Lancet Oncol 11(2): 121-128, 2010.

3 Zhou C, Wu YL, Chen G, Feng J, Liu XQ, Wang C, Zhang S, Wang J, Zhou S, Ren S, Lu S, Zhang L, Hu C, Luo Y, Chen L, Ye M, Huang J, Zhi X, Zhang Y, Xiu Q, Ma J and You C: Erlotinib versus chemotherapy as first-line treatment for patients with advanced egfr mutation-positive non-small-cell lung cancer (optimal, ctong-0802): A multicentre, open-label, randomised, phase 3 study. Lancet Oncol 12(8): 735-742, 2011

4 Rosell R, Carcereny E, Gervais R, Vergnenegre A, Massuti B, Felip E, Palmero R, Garcia-Gomez R, Pallares C, Sanchez JM, Porta R, Cobo M, Garrido P, Longo F, Moran T, Insa A, De Marinis F, Corre R, Bover I, Illiano A, Dansin E, de Castro J, Milella M, Reguart N, Altavilla G, Jimenez U, Provencio M, Moreno MA, Terrasa J, Munoz-Langa J, Valdivia J, Isla D, Domine M, Molinier O, Mazieres J, Baize N, Garcia-Campelo R, Robinet G, Rodriguez- 
Abreu D, Lopez-Vivanco G, Gebbia V, Ferrera-Delgado L, Bombaron P, Bernabe R, Bearz A, Artal A, Cortesi E, Rolfo C, Sanchez-Ronco M, Drozdowskyj A, Queralt C, de Aguirre I, Ramirez JL, Sanchez JJ, Molina MA, Taron M and Paz-Ares L: Erlotinib versus standard chemotherapy as first-line treatment for european patients with advanced egfr mutation-positive non-smallcell lung cancer (eurtac): A multicentre, open-label, randomised phase 3 trial. Lancet Oncol 13(3): 239-246, 2012.

5 Sequist LV, Yang JC, Yamamoto N, O'Byrne K, Hirsh V, Mok T, Geater SL, Orlov S, Tsai CM, Boyer M, Su WC, Bennouna J, Kato T, Gorbunova V, Lee KH, Shah R, Massey D, Zazulina V, Shahidi M and Schuler M: Phase iii study of afatinib or cisplatin plus pemetrexed in patients with metastatic lung adenocarcinoma with egfr mutations. J Clin Oncol 31(27): 3327-3334, 2013.

6 Wu Y-L, Zhou C, Hu C-P, Feng J, Lu S, Huang Y, Li W, Hou M, Shi JH, Lee KY, Xu C-R, Massey D, Kim M, Shi Y and Geater SL: Afatinib versus cisplatin plus gemcitabine for first-line treatment of asian patients with advanced non-small-cell lung cancer harbouring egfr mutations (lux-lung 6): An open-label, randomised phase 3 trial. Lancet Oncol 15(2): 213-222, 2014.

7 Oxnard GR, Arcila ME, Chmielecki J, Ladanyi M, Miller VA and Pao W: New strategies in overcoming acquired resistance to epidermal growth factor receptor tyrosine kinase inhibitors in lung cancer. Clin Cancer Res 17(17): 5530-5537, 2011.

8 Riely GJ, Kris MG, Zhao B, Akhurst T, Milton DT, Moore E, Tyson L, Pao W, Rizvi NA, Schwartz LH and Miller VA: Prospective assessment of discontinuation and reinitiation of erlotinib or gefitinib in patients with acquired resistance to erlotinib or gefitinib followed by the addition of everolimus. Clin Cancer Res 13(17): 5150-5155, 2007.

9 Chaft JE, Oxnard GR, Sima CS, Kris MG, Miller VA and Riely GJ: Disease flare after tyrosine kinase inhibitor discontinuation in patients with egfr-mutant lung cancer and acquired resistance to erlotinib or gefitinib: Implications for clinical trial design. Clin Cancer Res 17(19): 6298-6303, 2011.

10 Asami K, Okuma T, Hirashima T, Kawahara M, Atagi S, Kawaguchi T, Okishio K, Omachi N and Takeuchi N: Continued treatment with gefitinib beyond progressive disease benefits patients with activating egfr mutations. Lung Cancer 79(3): 276-282, 2013.

11 Nishino K, Imamura F, Morita S, Mori M, Komuta K, Kijima T, Namba Y, Kumagai T, Yamamoto S, Tachibana I, Nakazawa Y, Uchida J, Minami S, Takahashi R, Yano Y, Okuyama T and Kumanogoh A: A retrospective analysis of 335 japanese lung cancer patients who responded to initial gefitinib treatment. Lung Cancer 82(2): 299-304, 2013.

12 Faehling M, Eckert R, Kamp T, Kuom S, Griese U, Sträter J, Ott $\mathrm{G}$ and Spengler W: Egfr-tyrosine kinase inhibitor treatment beyond progression in long-term caucasian responders to erlotinib in advanced non-small cell lung cancer: A case-control study of overall survival. Lung Cancer 80(3): 306-312, 2013.

13 Park K, Tan E-H, O'Byrne K, Zhang L, Boyer M, Mok T, Hirsh V, Yang JC-H, Lee KH, Lu S, Shi Y, Kim S-W, Laskin J, Kim D-W, Arvis CD, Kölbeck K, Laurie SA, Tsai C-M, Shahidi M, Kim M, Massey D, Zazulina V and Paz-Ares L: Afatinib versus gefitinib as first-line treatment of patients with egfr mutation-positive nonsmall-cell lung cancer (lux-lung 7): A phase 2b, open-label, randomised controlled trial. Lancet Oncol 17(5): 577-589, 2016.

14 Sugawara S, Oizumi S, Minato K, Harada T, Inoue A, Fujita Y, Maemondo M, Yoshizawa H, Ito K, Gemma A, Nishitsuji M, Harada M, Isobe H, Kinoshita I, Morita S, Kobayashi K,
Hagiwara K, Kurihara M and Nukiwa T: Randomized phase ii study of concurrent versus sequential alternating gefitinib and chemotherapy in previously untreated non-small cell lung cancer with sensitive egfr mutations: Nej005/toog0902. Ann Oncol 26(5): 888-894, 2015.

15 Nakamura A, Inoue A, Morita S, Hosomi Y, Kato T, Fukuhara T, Gemma A, Takahashi K, Fujita Y, Harada T, Minato K, Takamura $\mathrm{K}$, Kobayashi $\mathrm{K}$ and Nukiwa $\mathrm{T}$ : Phase iii study comparing gefitinib monotherapy $(\mathrm{g})$ to combination therapy with gefitinib, carboplatin, and pemetrexed (gcp) for untreated patients (pts) with advanced non-small cell lung cancer (nsclc) with egfr mutations (nej009). J Clin Oncol 36(15): 9005-9005, 2018.

16 Eisenhauer EA, Therasse P, Bogaerts J, Schwartz LH, Sargent D, Ford R, Dancey J, Arbuck S, Gwyther S, Mooney M, Rubinstein L, Shankar L, Dodd L, Kaplan R, Lacombe D and Verweij J: New response evaluation criteria in solid tumours: Revised recist guideline (version 1.1). Eur J Cancer 45(2): 228-247, 2009.

17 Yang JCH, Sequist LV, Zhou C, Schuler M, Geater SL, Mok T, Hu CP, Yamamoto N, Feng J, O'Byrne K, Lu S, Hirsh V, Huang Y, Sebastian M, Okamoto I, Dickgreber N, Shah R, Märten A, Massey D, Wind S and Wu YL: Effect of dose adjustment on the safety and efficacy of afatinib foregfrmutation-positive lung adenocarcinoma:Post hocanalyses of the randomized lux-lung 3 and 6 trials. Ann Oncol 27(11): 2103-2110, 2016.

18 Kato T, Yoshioka H, Okamoto I, Yokoyama A, Hida T, Seto T, Kiura K, Massey D, Seki Y and Yamamoto N: Afatinib versus cisplatin plus pemetrexed in japanese patients with advanced nonsmall cell lung cancer harboring activatingegfrmutations: Subgroup analysis of lux-lung 3. Cancer Sci 106(9): 1202-1211, 2015.

19 Mok TS, Wu Y-L, Ahn M-J, Garassino MC, Kim HR, Ramalingam SS, Shepherd FA, He Y, Akamatsu H, Theelen WSME, Lee CK, Sebastian M, Templeton A, Mann H, Marotti M, Ghiorghiu S and Papadimitrakopoulou VA: Osimertinib or platinum-pemetrexed in egfr $\mathrm{t} 790 \mathrm{~m}$-positive lung cancer. $\mathrm{N}$ Engl J Med 376(7): 629-640, 2017.

20 Soria J-C, Wu Y-L, Nakagawa K, Kim S-W, Yang J-J, Ahn M-J, Wang J, Yang JC-H, Lu Y, Atagi S, Ponce S, Lee DH, Liu Y, Yoh K, Zhou J-Y, Shi X, Webster A, Jiang H and Mok TSK: Gefitinib plus chemotherapy versus placebo plus chemotherapy in egfr-mutation-positive non-small-cell lung cancer after progression on first-line gefitinib (impress): A phase 3 randomised trial. Lancet Oncol 16(8): 990-998, 2015.

21 Mok TSK, Kim SW, Wu YL, Nakagawa K, Yang JJ, Ahn MJ, Wang J, Yang JC, Lu Y, Atagi S, Ponce S, Shi X, Rukazenkov Y, Haddad V, Thress KS and Soria JC: Gefitinib plus chemotherapy versus chemotherapy in epidermal growth factor receptor mutation-positive non-small-cell lung cancer resistant to first-line gefitinib (impress): Overall survival and biomarker analyses. J Clin Oncol 35(36): 4027-4034, 2017.

22 Katakami N, Atagi S, Goto K, Hida T, Horai T, Inoue A, Ichinose Y, Koboyashi K, Takeda K, Kiura K, Nishio K, Seki Y, Ebisawa R, Shahidi M and Yamamoto N: Lux-lung 4: A phase ii trial of afatinib in patients with advanced non-small-cell lung cancer who progressed during prior treatment with erlotinib, gefitinib, or both. J Clin Oncol 31(27): 3335-3341, 2013.

Received June 20, 2018

Revised June 27, 2018

Accepted June 29, 2018 